\title{
ACUTE DISSEMINATED HISTOPLASMOSIS WITH A REPORT OF A CASE OCCURRING IN ENGLAND*
}

\author{
BY \\ F. C. POLES AND J. D. O'D. LAVERTINE \\ From Edgware General Hospital
}

(RECEIVED FOR PUBLICATION MAY 7, 1954)

Histoplasmosis, an acute, subacute, or chronic infection caused by the fungus Histoplasma capsulatum, is now known to occur sporadically in most countries of the world (Mochi and Edwards, 1952). It is endemic in a large area of North America, and to a lesser extent in Central and South America. The fungus may give rise to a variety of clinical syndromes (Beadenkopf and Loosli, 1951 ; Christie, 1951). Israel, De Lamater, Sones, Willis, and Mirmelstein (1952) distinguish four principal types of the disease. Active primary histoplasmosis, usually benign, is responsible for few symptoms, and is thus rarely diagnosed. Healed primary histoplasmosis is common in endemic areas and may be diagnosed by a positive histoplasmin skin test; it is frequently accompanied by radiological evidence of pulmonary calcification (Christie and Peterson, 1946 ; Furcolow, High, and Allen, 1946 ; Palmer, 1946 ; Prior and Allen, 1947 ; Bunnell and Furcolow, 1948). Acute disseminated histoplasmosis is often rapidly fatal with involvement of the tongue, larynx, reticulo-endothelial system, and adrenal glands as well as the lungs. This form is seen most commonly in infants, in the aged, or in those debilitated by tuberculosis or malignant disease. Finally, chronic disseminated histoplasmosis, commonly involving the skin, oropharynx, larynx, lungs, and lymph nodes, is in many cases ultimately fatal but arrest and recovery have been recorded in some instances.

\section{REVIEW OF THE LITERATURE}

As the disease is endemic in the central and eastern parts of North America, most of the literature has originated in the United States.

Darling, in 1906, was the first to describe a fatal disease due to an organism producing pseudotubercles in the lungs, and focal necroses in the liver, spleen, and lymph nodes. At this time he considered that the organism was a protozoon, and proposed the name Histoplasma capsulatum. Interest was reawakened in 1934, when De

* Based on a paper read before the Thoracic Society in London in March, 1954.
Monbreun cultured the organism and proved it to be a fungus; and finally Conant, in 1941, described its life cycle.

In 1945 Parsons and Zarafonetis described seven patients with histoplasmosis and reviewed 71 reported cases of the disseminated type, stressing their clinical aspects. They believed that the infection was "almost universally fatal," but Bunnell and Furcolow in 1948 reported 10 further cases and showed that recovery may occur, even in those patients with a severe clinical illness. By 1950 Rodger, Terry, and Binford found that of 141 patients reported in the literature, 23 had recovered. Several of these had suffered from the acute disseminated type of the disease (Jelliffe, 1949 ; Blumberg, Ruchman, and Johansmann, 1949 ; Furcolow, 1950 ; Klingberg, 1950 ; Wheeler, Friedman, and Saslaw, 1950). Hodgson, Weed, and Clagett (1950) reviewed published necropsy reports and concluded that the ulcerative lesions have no characteristic appearance, the diagnosis depending on the recognition of the fungus in culture, or in biopsy material. Puckett (1953), in a study of lung tissue removed at operation, was able to make a confident diagnosis on the morphological characteristics of the organism. He suggested the terms "granuloma" and "multiple granulomata due to $\boldsymbol{H}$. capsulatum" as descriptive terms for the lung changes found.

Up to the end of 1948, 104 of the 136 known cases were in the United States, and only five in Europe. Of the latter, only one had been diagnosed in England, and was reported by Derry, Card, Wilson, and Duncan in 1942 . This patient was in France when he developed his symptoms but had been living in England until four months previously; he had lived in India and the Sudan four years before his illness. Since then, six other accounts have appeared in the English literature. Duncan (1947) has reported a case of cutaneous histoplasmosis probably of West African origin. Hutchison (1952) described a patient with laryngeal histoplasmosis whom he considers to have 
been infected in the Far East. Arblaster (1950), Crofton (1950), and Sakula (1953) recorded healed primary histoplasmosis in four patients who had lived in Canada and in the United States. Locket, Atkinson, Grieve, and Bridson (1953) made an ante-mortem diagnosis of disseminated histoplasmosis in a seaman who had travelled in the Near East and had also visited Durban and Bombay but who had lived in England for seven years before his fatal illness. Limerick's (1951) unconfirmed case of abdominal histoplasmosis, apparently contracted in this country, must remain doubtful. Thus, in Britain, the condition is a rarity, and particularly as a locally acquired disease; the infection to be described is thought to have been contracted in England.

\section{CASE Report}

A man aged 45, a clerk in the Post Office, was referred to the Edgware Chest Clinic on May 1, 1951, with a history of sore throat, loss of voice and hoarseness for five months, but no cough or sputum. His general health had not suffered and he had remained at work. A chest radiograph was at this time considered to show no evidence of active disease. It showed a small calcified focus, $3 \mathrm{~mm}$. in diameter, in the left mid zone, with deposits of calcium in the left hilar glands. In a retrospective study of this film, however, a few miliary deposits were apparent, mainly in the right lower and left upper zones. Mr. A. Miller examined the larynx and found a swelling of the left vocal cord extending into the arytenoid region. The swelling looked friable and was suggestive of a neoplasm. By direct laryngoscopy the swelling could be seen to extend beyond the arytenoids towards the cricoid region but there was no intratracheal extension. A piece was removed for biopsy. No enlarged lymph-nodes were present at this time.

Enquiries into his past history revealed that he had served in France in 1939, in Nigeria in 1942, and in Burma in 1944. During this period he had had no illness except jungle sores. He never visited the United States or Canada and returned to his home in Stanmore in 1945. The laryngeal biopsy performed on Nay 15 showed fragments of non-specific granulation tissue in which histiocytes were present containing minute, encapsulated, yeast-like bodies, morphologically resembling $H$. capsulatum. No evidence of carcinoma or tuberculosis was seen.

Examination of the blood gave haemoglobin $80 \%$ (Haldane); erythrocytes 4,120,000, leucocytes 2,400 per c.mm. (polymorphonuclear neutrophils $50 \%$, eosinophils $5 \%$, lymphocytes $40 \%$, monocytes $5 \%$ ). The Wassermann reaction was negative. An intradermal test with histoplasmin 1 in 100 was negative. Marrow from a sternal puncture showed normal cytology; no fungi were seen, and cultures and animal inoculation were negative. The chest radiograph now showed a fine reticulation of all zones of both lungs.

The laryngeal condition remained unaltered for $a$ 을 month, after which a further biopsy was carried out $\underline{\underline{D}}$ with a view to obtaining a culture of the organism. $\frac{\bar{\omega}}{\vec{D}}$ Histological examination of half the specimen showed $\underset{\varnothing}{\varnothing}$ two ill-defned epithelioid tubercles with giant cells, 잉 while yeast like organisms were apparent only on its $\infty$ surface. The culture was heavily overgrown with $\vec{\circ}$

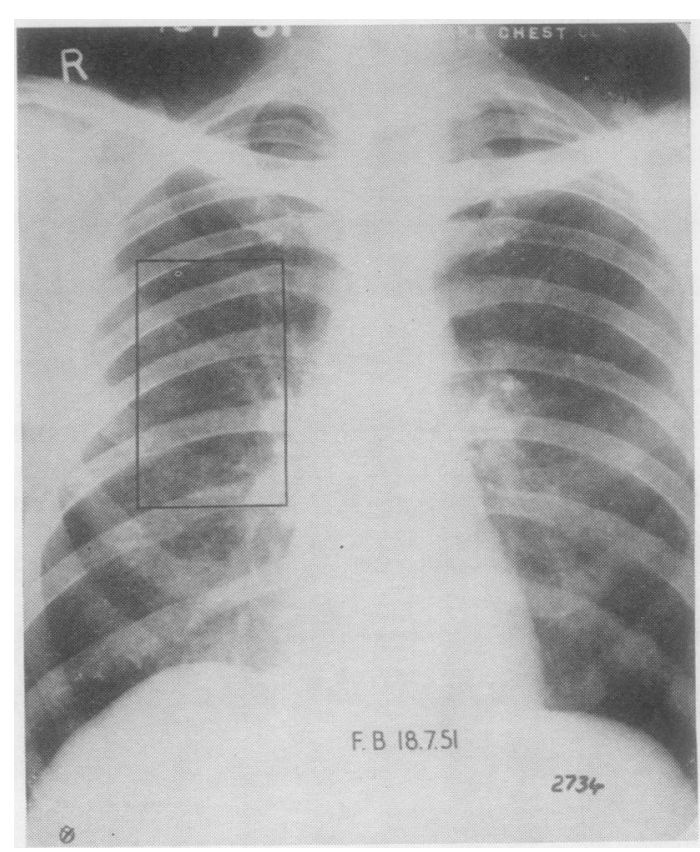

FIG. 1a.-Radiograph of the chest, July 18, 1951, showing miliary shadows in all zones.

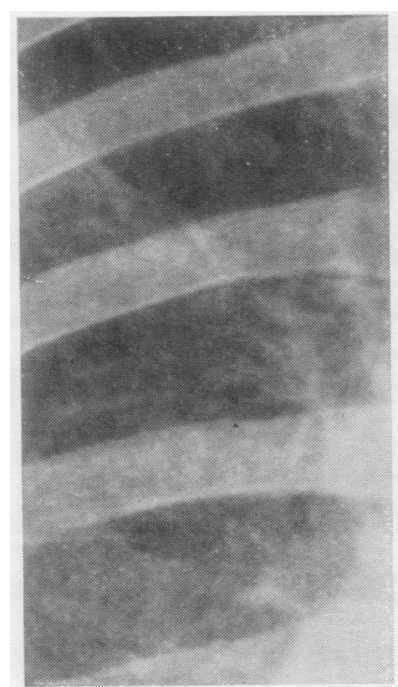

FIG. 1b.-Marked area in Fig. 1, showing detail of shadows. contaminating bacteria; a few colonies of Candida albicans were pre- 3 sent. No growth of $H$. capsulatum was을
obtained.

Shortly after this은 second biopsy the pa- $>$ tient began to suffer음 from more generalized symptoms, namely, os fever, lassitude, loss of $N$ weight, cough, dys- 스 pnoea, and intermittent $\omega$ diarrhoea. He had an evening pyrexia ofo $102^{\circ} \mathrm{F}$. and a tachy-ฮ̄ cardia of 130 per min. $\stackrel{?}{?}$ There were no abnor- 0 mal physical signs in the chest and no en- $\mathbb{\mathbb { D }}$ larged lymph - nodes, $\frac{\text { ते }}{\mathbb{6}}$ but the spleen waso enlarged to three finger-? 
breadths below the costal margin, and the liver edge was palpable. Examination of the thyroid, breasts, and rectum showed no evidence of new growth. Mantoux tests $(1: 1,000$ and $1: 100$ O.T.) were negative, and a histoplasmin test was performed twice with negative results. At this time the chest radiograph showed a generalized miliary mottling as well as the reticular shadows (Figs. $1 a$ and $1 b$ ). Tomography showed three scattered deposits of calcium at the left apex ranging from $2 \mathrm{~mm}$. to $6 \mathrm{~mm}$. in diameter.

In view of the findings from the second laryngeal biopsy, and the failure to culture the fungus, an alternative diagnosis of acute miliary tuberculosis had now to be considered. On the assumption that miliary tuberculosis is treatable, while other conditions giving rise to miliary infiltration in the lungs are not, streptomycin, $1 \mathrm{~g}$. daily with sodium paraminosalicylate acid $15 \mathrm{~g}$. daily, was given from July 19 . Sputum, laryngeal swabs, and resting gastric juices were all examined and found free from acid-fast bacilli microscopically, but the negative culture results were not available until after death. Cerebrospinal fluid was normal in every respect. The patient continued to run a high swinging fever, but the diarrhoea ceased, and the spleen decreased in size during the first two to three weeks of streptomycin treatment. He then began to deteriorate rapidly with increasing loss of weight, and gradually developed moist sounds over most of the right side of the chest and at the left base. A further radiograph showed mottled shadows throughout both lung fields, most marked medially, diminishing towards the periphery, and becoming confluent at the right base; there was no obvious hilar adenopathy (Figs. $2 a$ and $2 b$ ). About this time the spleen started to enlarge again, although there were still no palpable lymph nodes. On August 24 he became disorientated, but showed no abnormal physical signs in the central nervous system. A further lumbar puncture gave a cerebrospinal fluid pressure of $66 \mathrm{~mm}$. water; the fluid contained a normal number of cells, but chlorides were reduced to $560 \mathrm{mg}$. per $100 \mathrm{ml}$. The urine showed a chloride excretion of $9 \mathrm{mg}$. per $100 \mathrm{ml}$., the blood pressure was $90 / 50$, and no abnormal skin pigmentation was present. He was treated with large doses of sodium chloride, but no adrenal cortical hormones were given. The systolic blood pressure rose to between 95 and $110 \mathrm{~mm} . \mathrm{Hg}$, and that evening the patient appeared very much better mentally and was able to read. Despite this he died suddenly at 2 a.m. on the morning of August 25, 1951.

NECROPSY FINDINGS. - A necropsy was performed on August 27, 57 hours after death. The body was that of a very emaciated middle-aged man. The larynx showed heaping up of the mucosa, accompanied by superficial ulceration involving the vocal cords and much of the posterior and lateral walls. A similar circular lesion, $\frac{1}{4}$ in. in diameter, was situated in the right pyriform fossa, and another astride the tracheal bifurca tion. The lungs were bulky owing to oedema, and all lobes showed irregular miliary yellowish-grey nodules becoming confluent particularly in the lower lobes. There was a little fibrosis, but no cavitation. The pleura was firmly adherent over most of the left lung, and to a lesser extent over the right. The tracheobronchial lymph-nodes were slightly enlarged and soft, and showed no evidence of caseation. The liver was moderately enlarged $(2,531$ g.) and presented a pale, swollen cut surface with the normal pattern blurred.

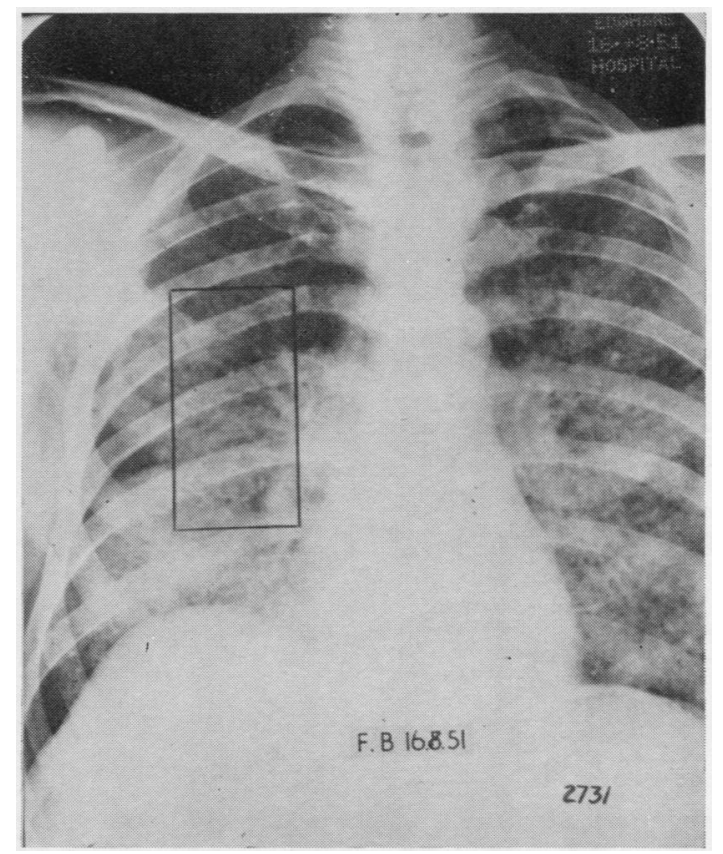

FIG. $2 a$-Radiograph of the chest, August 16, 1951, showing extensive soft shadows becoming confluent at the right base.

There was considerable enlargement of the spleen $(630 \mathrm{~g}$.$) ,$ but the cut surface was normal in appearance. The adrenal glands were the most strikingly abnormal feature being gross. ly enlarged (c o m bined weight $110 \mathrm{~g}$.) and replaced almost entirely by a mass of necrotic granulation tissue, which appeared to be formed by the coalescence of smaller nodules.

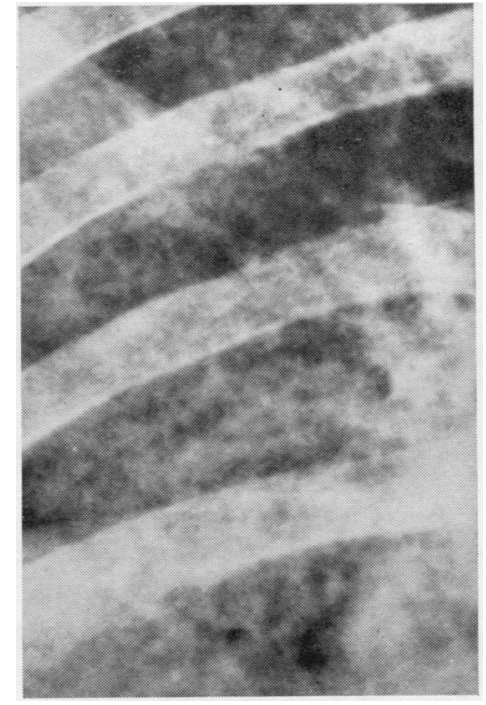

FIG. 2b.-Marked are $z$ in Fig. $2 a$, showing detail of shadows. 


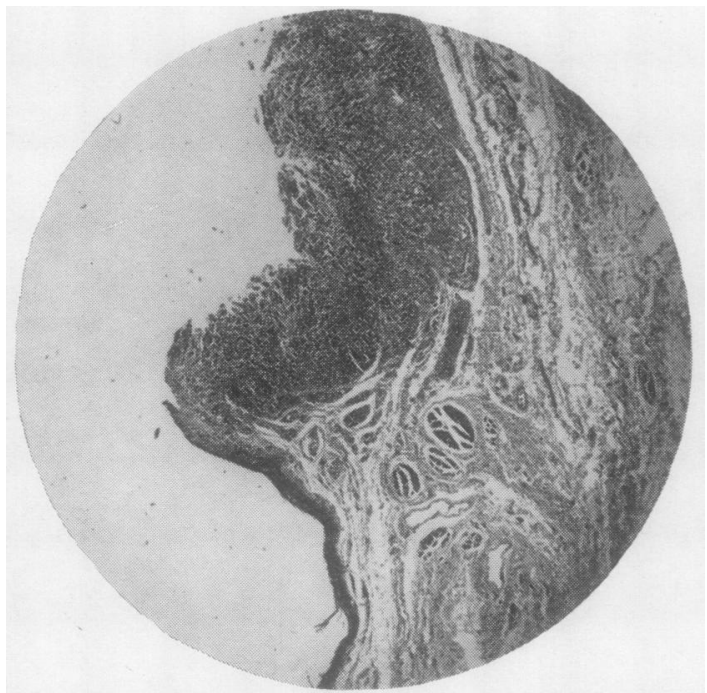

FiG. 3

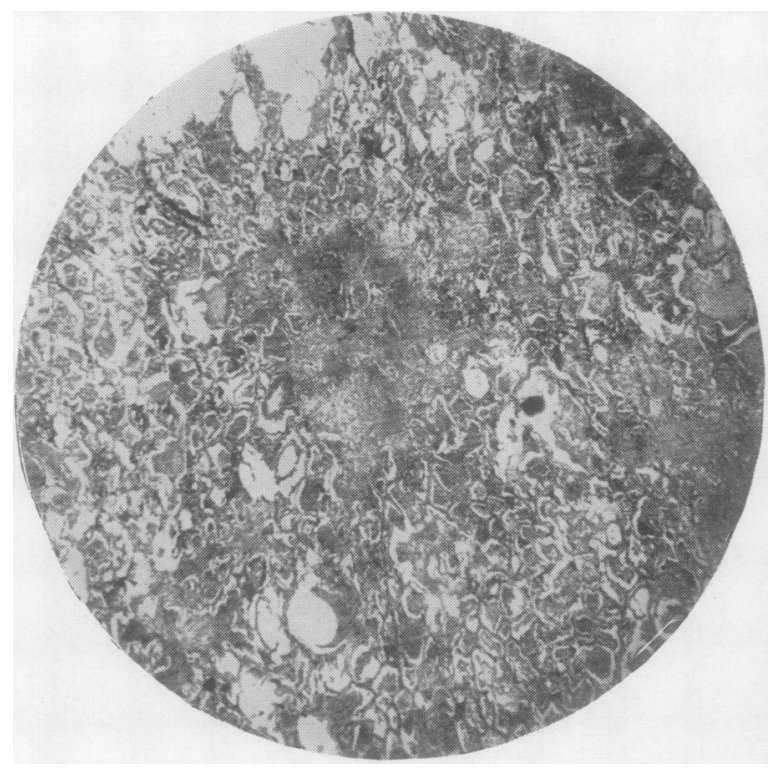

Fig. 5

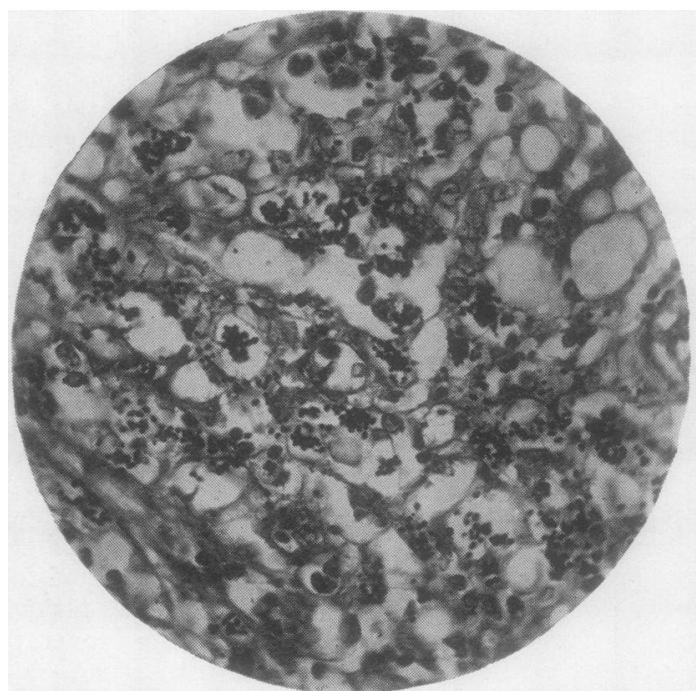

Fig. 4

Fig. 3.-Photomicrograph of laryngeal ulcer showing the raised edge and the tase of granulation tissue. (Haematoxylin and eosin. $\times$ 13.)

Fig. 4.-F hotomicrograph of granulation tissue from the base of the laryngeal ulcer showing yeast cells in histiocytes and free in the tissue spaces. (Haematoxylin and eosin. $\times 175$.)

FIG. 5.-Photomicrograph of lung showing local areas of necrosis $\overrightarrow{\overrightarrow{0}}$ and inflammatory exudate filling the adjacent alveoli. (Haemaoxylin and eosin. $\times 13$.)

Fig. 6.-Photomicrograph of lung showing yeast cells, many within macrophages. (Gram. $\times 300$.)

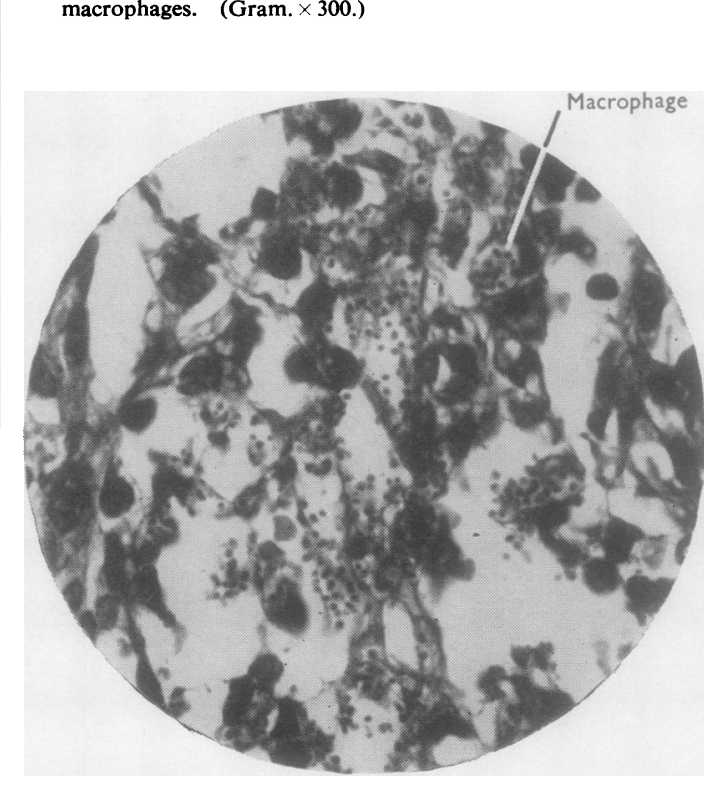

FiG. 6 
Fig. 7.-Photomicrograph of adrenal gland showing the remaining secretory cells and a part of the mass of necrotic tissue. A narrow band containing inflammatory cells packed with yeasts separates these two zones. (Haematoxylin and eosin. $\times 200$.)

FiG. 8.-Photomicrograph showing the doubly refactile nature of the "capsule" to polarized light $(\times 1,700)$.

FIG. 9.-Photomicrograph showing several encapsulated yeast cells, some showing " budding." (Giemsa. $\times 1,000$.)

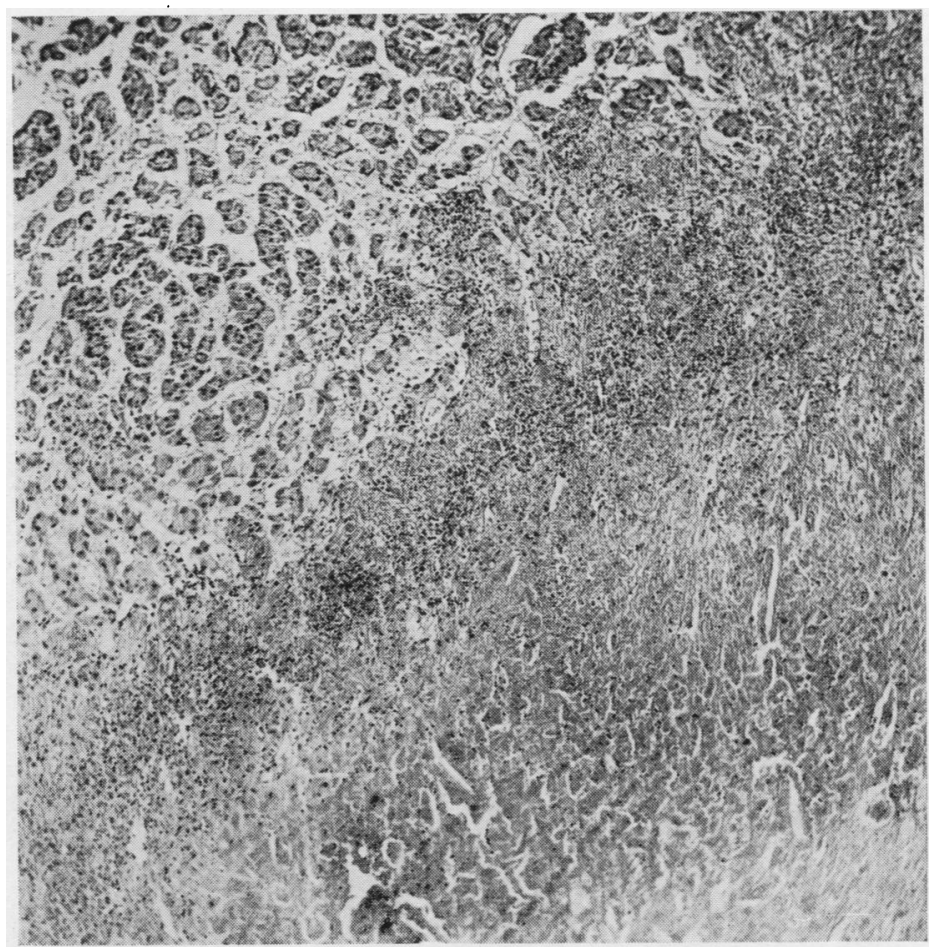

Fio. 7
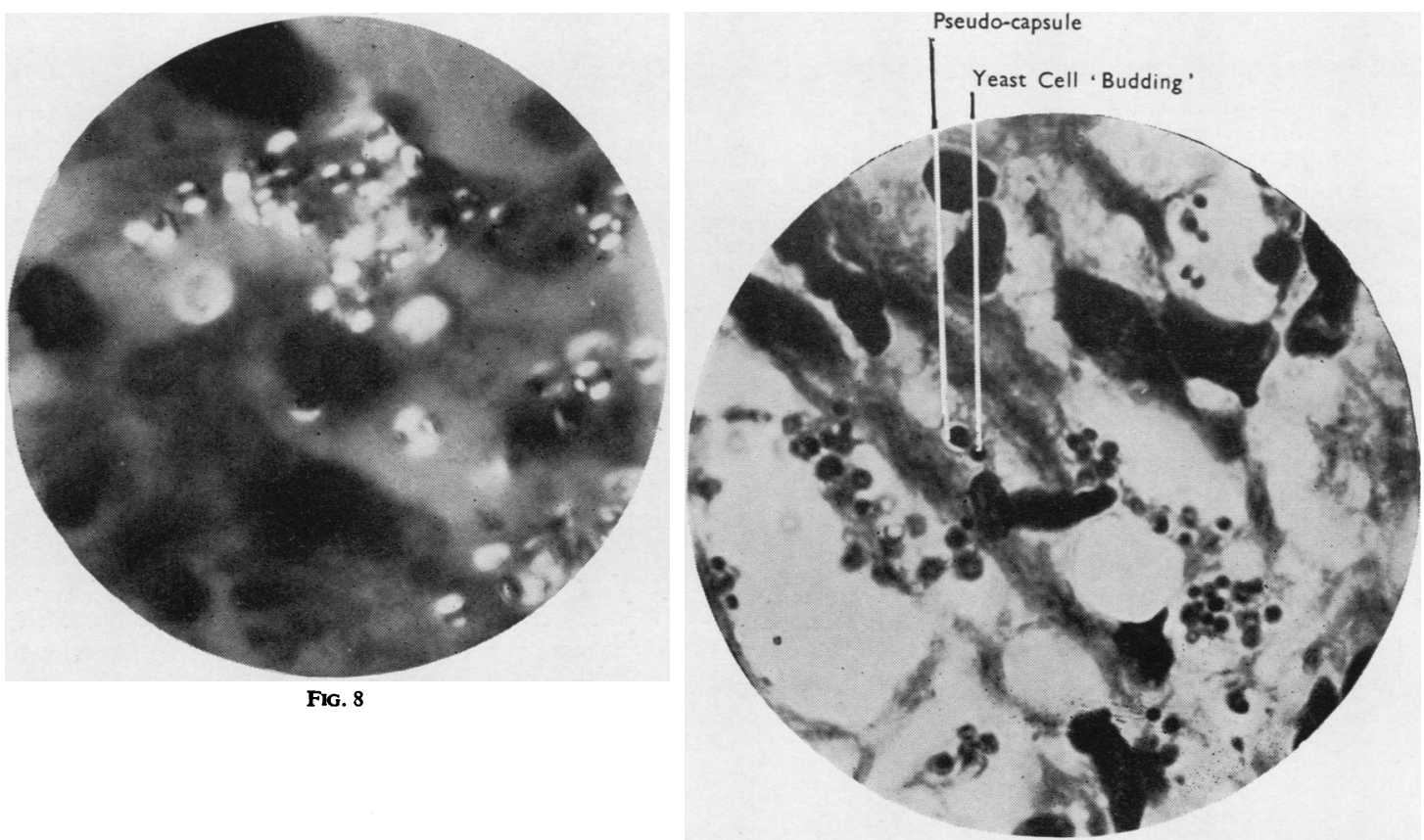

Fig. 9

Fig. 8 
No significant abnormality was found in the cardiovascular, alimentary, or urogenital systems. The central nervous system was not examined.

Histological Examination.-The base of the laryngeal and tracheal ulcers consisted of granulation tissue, similar to that seen in the first biopsy, containing large numbers of yeast-like cells situated both intracellularly and free in the tissues (Figs. 3 and 4). The lungs showed a patchy pneumonic process, with fibrin and miscellaneous inflammatory cells in the alveoli, and congestion, with chronic inflammatory infiltration of the interstitial tissue. Many of the alveolar lining cells showed cubical metaplasia and there were several foci of necrosis in which the outlines of lung tissue were just discernible (Fig. 5). Among the inflammatory cells were a number of yeast-containing macrophages (Fig. 6). The adrenals showed a similar necrotic process in advanced degree, destroying most of the secretory tissue, and there were many yeast laden cells at the margin of the necrotic area (Fig. 7). The lymph-nodes showed sinus catarrh, the spleen congestion of the pulp, and the liver toxic degeneration of the parenchyma, accompanied by scanty lymphocytic infiltration of the portal tracts. Yeasts however were absent from these three organs. No acid-fast bacilli could be discovered in any of the stained sections.

\section{Discussion}

The differential diagnosis from tuberculosis in the absence of confirmatory pathological tests, and the value of laboratory tests in the diagnosis of acute histoplasmosis, were the main problems during this patient's illness, and merit further consideration.

Differential Diagnosis.-The difficulty in differentiating a tuberculous infection from one due to histoplasmosis has been emphasized by several authors (Meleney, 1940 ; Parsons and Zarafonetis, 1945 ; Hodgson and others, 1950 ; Christie, 1951) ; the two infections have been found associated in 13 cases. Curtis and Grekin (1947) believe that any granulomatous condition acts as a predisposing factor to fungous invasion.

Both granulomatous and ulcerative lesions of the larynx due to $H$. capsulatum have been reported, varying in nature from small papillomatous masses associated with oedema of the arytenoid area, to extensive ulceration and infiltration of the larynx, and even the epiglottis. Such lesions may be primary, as were those reported by Dean (1942), Gammell and Breckenridge (1949), Roberts and Forman (1950), and Hutchison (1952), or may result from bloodborne dissemination (Parsons and Zarafonetis, .1945). Hulse (1951), referring to the differential diagnosis of lesions due to tuberculosis and to histoplasmosis, pointed out that microscopically the two may closely resemble each other, unless such special procedures as specific tissue stains and tissue cultures are used. He emphasizes that laryngeal tuberculosis is always secondary to open pulmonary tuberculosis, and always responds, at least to some extent, to streptomycin.

The patient under discussion presented with a mass in the region of the left arytenoid cartilage, which was shown by biopsy to be an inflammatory granuloma. Specific tissue stains were not used at that stage, and the yeast-like organisms in the tissues were not identified. Clinically, however, the laryngeal mass did not conform to the more common types of tuberculous process, and, in retrospect, resembled more closely mucosal lesions reported in cases of histoplasmosis.

It was necessary also to consider the diagnostic significance of the acute constitutional upset associated with the miliary shadows seen in the later chest radiographs.

Furcolow, Mantz, and Lewis (1947) state that there is no typical radiological picture in histoplasmosis. About two-thirds of their 72 cases showed a nodular, sharply circumscribed radiographic shadow. Another frequent finding was a patchy infiltration, often widely disseminated, which later sometimes became nodular. In a few, hilar lymph-node enlargement only was present. In the acute disseminated type of the disease, Hodgson and others (1950) found all types of radiographic shadows including fine reticulation and miliary mottling. Only rarely has a cavity been reported (High, Zwerling, and Furcolow, 1947 ; Schwartz and Spitz, 1952; Charr, 1953). The mulberry-like and the "halo" primary foci as previously described in pulmonary histoplasmosis are no longer considered diagnostic of this condition. In all types, with the exception of the fatal fulminating systemic infection, pulmonary lesions usually calcify. Sontag and Allen (1947), in a study of infected children in an endemic area, found that calcification was frequently seen radiologically one to three years after infection, and occasionally after a few months, but might take as long as six years to appear. In over one-third of the children the lesions were progressive over several years, new radiological shadows appearing while older ones calcified. They also found that calcifications due to tuberculosis and to histoplasmosis were indistinguishable. Silverman (1950) states that the only radiological finding which might be attributed with any degree of probability to a 
$H$. capsulatum infection is disseminated intrathoracic calcification. In endemic areas $93.5 \%$ of such cases show a positive histoplasmin skin test (High and others, 1947), and a similar relationship exists even in non-endemic areas (Absher and Cline, 1949). It is, however, accepted that tuberculosis may give rise to similar radiological findings. Unlike those of tuberculosis the localized lesions of histoplasmosis are not more common in the upper zones, and cavitation only rarely occurs. Diagnosis becomes even more difficult when the two conditions are associated. In such instances both organisms have occasionally been isolated (Rodger and others, 1951 ; Charr, 1953), but generally the dual infection has been recognized only at necropsy.

In the case under discussion the radiological changes and the severe constitutional disturbance could have been caused equally well by histoplasmosis or tuberculosis.

The adrenal glands may be destroyed in both tuberculosis and histoplasmosis. In the former, it is only rarely found in association with acute pulmonary disease, while in disseminated histoplasmosis the adrenals are very commonly found to be involved at necropsy, though clinical evidence of adrenal damage has not often been recorded during life (Thomas and Morehead, 1943 ; Parsons and Zarafonetis, 1945; Charr, 1953). Locket and others (1953), realizing that adrenal failure was likely to occur in their patient, carried out full biochemical tests daily for some weeks. The results of all these tests were normal, the patient dying suddenly of acute adrenal failure without warning signs or symptoms. LeJeune (1950) referred to a patient with a laryngeal lesion due to histoplasmosis who recovered but later developed Addison's disease. Rawson, Collins, and Grant (1948), in a review of 19 cases, found that in nine massive destruction of the adrenal glands was present at necropsy. Some of these patients showed possible symptoms of adrenal insufficiency during life, such as weakness, anorexia, and loss of weight out of proportion to the degree of fever. Such symptoms were usually masked by others; a fall in blood pressure was a terminal finding occurring too late to be of assistance in diagnosis. Such was the sequence of events in the case described above, the adrenal lesion remaining unsuspected until 24 hours before death in spite of almost complete necrosis of glandular tissue found at necropsy.

The absence of tubercle bacilli from the sputum of a man with a granulomatous laryngeal lesion whose chest radiograph at first appeared normal, and who later developed extensive lung changes associated with a rapid enlargement of the liver and spleen, should have provoked a more intensive effort to culture the fungus. Massive replacement of the adrenal glands by granulation tissue, with mucomembranous and lung lesions, and an enlarged liver and spleen, are a well-recognized combination of lesions at necropsy in acute disseminated histoplasmosis. The failure of the fungus to invade the reticulo-endothelial system in this patient was, however, an unusual feature.

Signs of dissemination have been noticed on several occasions to follow a biopsy. The initial apparent response to streptomycin was misleading. It is unlikely that the further administration of this drug adversely influenced the outcome, as may occur with some antibiotics in other types of fungus infections, since the disease was generalized before treatment was started. Furthermore, Campbell and Saslaw (1951) have demonstrated the failure of streptomycin to enhance the infectivity of $H$. capsulatum in mice.

Diagnostic Tests.-Once histoplasmosis has been suspected clinically, it should usually be possible to confirm the diagnosis histologically or by culture. The histoplasmin intradermal test and the complement-fixation test may provide useful additional information.

In the patient described the final diagnosis rested entirely on histological grounds. Even in the absence of positive cultures, the histological appearance of the organism is sufficiently characteristic to allow a diagnosis to be made with a reasonable degree of reliability. In the haematoxylin and eosin sections, the fungus was visible as a slightly basophil oval mass varying from 2 to $5 \mu$ in size, often surrounded by a clear refractile capsule. The doubly refractile nature of this capsule to polarized light was demonstrated (Fig. 8). The yeasts were seen within reticulo-endothelial cells, and also free in the tissues. In areas where the fungus was scanty, its presence was missed, as it stained only weakly with haematoxylin. Later, when the periodic-acid-Schiff stain was used, which stains fungi avidly, these scanty organisms were made apparent. Inconstantly a small percentage of the yeast cells may be weakly acidfast; this was demonstrated in the post-mortem material. The morphology of the fungus was best demonstrated by Giemsa's stain, by which " budding" and vacuolation of cell cytoplasm were well shown (Fig. 9). Differentiation from other mycoses, such as blastomycosis and coccidioidomycosis was made on morphological grounds. Leishmaniasis was excluded by showing the appa- 
rent capsulation of the organism and its positive staining by the periodic-acid-Schiff method.

The fungus failed to grow in cultures made during life from laryngeal biopsy material and bone marrow. A positive culture is readily obtained in most instances of acute disseminated disease ; but Locket and others (1953) experienced some difficulty until they altered the $p \mathrm{H}$ of their media. Pratt, Schwartz, and Ehrlich (1950) obtained the fungus from aspirated bone marrow in 11 of 23 proven cases. The negative cultures from our patient were both unexpected and misleading; bronchial secretions were not cultured for the fungus.

In the patient we have described, the histoplasmin skin reaction was negative on three occasions. The first was performed five months after the onset of local symptoms when the patient's general condition was excellent, the other two tests were carried out about one month before death when dissemination had occurred. Although for a resident in Britain a positive reaction is a valuable diagnostic finding, a negative result does not exclude a diagnosis of acute histoplasmosis. Hulse's patient, who was very similar to our own, had a negative reaction, and Hodgson and others (1950), in a series of 24 cases, found that only half showed positive skin sensitivity. Furcolow, Emge, and Bunnell (1948) pointed out that a critical illness will exert a depressing effect on the skin sensitivity to histoplasmin as well as to tuberculin, and the reaction may become positive only when the patient starts to improve Christie (1951) believes that cross-reactions with other fungi are not of any practical importance in the interpretation of histoplasmin sensitivity tests in man, provided a critical dilution of the antigen is used.

The complement-fixation test was used by Bunnell and Furcolow (1948) and Furcolow (1949) but they found it to be unreliable. Hodgson and others (1950) consider that cross-reactions in other fungous infections render it useless, and Christie (1951) points out that massive infection may suppress the antibody titre. However, Salvin (1947) and Tenenberg and Howell (1948) have shown the test to be useful in some acute fulminating cases, a high or rising titre being diagnostic. This test was not used, but might have proved helpful in this particular case.

EPIDEMIOLOGY.-The epidemiology of histoplasmosis is still largely unknown. The fungus has been isolated from soil (Emmons, 1949), and also from various animal hosts (De Monbreun, 1939;
Prior, Cole, and Torbet, 1949), but it has never been proved that animal reservoirs have been responsible for human outbreaks of the disease (Olson, Bell, and Emmons, 1947). Likewise, man-to-man infection has not so far been shown to occur. The fungus is assumed to be dust borne, and small outbreaks of pulmonary infection have occurred amongst men working in dusty occupations in areas of America where the histoplasmin sensitivity is low. These men were working in damp sites where conditions were satisfactory for the growth of fungus (Schwartz and Spitz, 1952).

The incubation period is uncertain. Some authors (Schultz, 1937; Kirsch, 1951) consider that the fungus may live as a parasite in the body for many years before producing symptoms, and believe that further tissue injury is necessary before the disease becomes manifest. These views were apparently based on the fact that $H$. capsulatum was unknown in Europe at that time. Hutchison (1952) was of the opinion that in his patient the infection was acquired in the Far East some 14 years before the onset of symptoms, on the grounds that the advance of the disease was slow and the fungus was undergoing destruction in considerable numbers. However, Brandt (1950) has shown in experimental infections with the South African strain, which does not cause systemic disease, that destruction of the yeasts in the tissues starts very soon, and that by the twentieth day it is difficult to find intact forms. Moreover, recent, although limited, histoplasmin surveys carried out in Africa, India, Hong Kong, and Europe have given positive results in less than $2 \%$ of persons tested in all these areas, with the exception of surveys in Kenya, where $8.5 \%$ were positive (Stott, 1954), and in Durban, where $5.9 \%$ were positive (Mochi and Edwards, 1952). There is not, therefore, any strong evidence to support the hypothesis that infection is more likely to be acquired in the East than in Britain.

The opinion in America, among physicians who have had much experience with the condition, ise that the incubation period is comparatively short. Heilbrunn and Cain (1950) believe that symptoms probably occur about 10 weeks after infection. Schwartz and Spitz (1952) studied an epidemic of the infection and found that symptoms occurred in one to two weeks, that radiological signs reached their maximum in two to six weeks, and often remained at that intensity for six months. Furcolow (1952), as the result of a study of a large number of cases over seven years, considers that the infection is acute, and that symptoms 
develop four to six weeks after exposure to infection, the histoplasmin test converting after the same period. He believes that relapses do not occur as with tubercu'osis, though he states that the evidence for this is not yet conclusive ; Ajello (1952) and Emmons (1952) share this view. No example of a healed calcified lung lesion due to $H$. capsulatum relapsing with blood-stream dissemination has been reported. Thus, the evidence would suggest that, in the acute forms of the disease at least, the incubation period is relatively short.

We believe that the calcified pulmonary foci in the patient described were not due to histoplasmosis. Pulmonary calcification is not seen in acute systemic histoplasmosis, and healed calcified lesions are usually associated with a positive skin sensitivity. We conclude, therefore, that this man acquired his fatal histoplasma infection in England, probably shortly before an "influenza-like" illness at the close of 1950 . We have no suggestions to make as to the source of infection, for he kept no pets, his occupation was not a dusty one, and he did not handle any parcels from America. It is unlikely that a local soil infection was present as the other members of his family are histoplasmin negative.

\section{SUMMARY}

A fatal case of acute disseminated histoplasmosis affecting the larynx, lungs, and adrenals is described.

Histoplasmin tests were negative, and biopsy material and sternal marrow failed to produce the causative fungus on culture. The diagnosis was suspected histologically on examination of the laryngeal biopsy material, and confirmed histologically at necropsy.

The differential diagnosis from tuberculosis is discussed.

It is suggested that the infection was acquired in England.

We wish to acknowledge our debt and appreciation to Dr. R. W. Riddell for his help in identifying the parasitic phase of the fungus, and for his suggestions and encouragement in many other ways. For the photomicrographs we should like to thank Mr. D. F. Kemp of the Photographic Department, Institute of Diseases of the Chest.
We wish also to express our thanks to Mr. A. Miller for his report on the larynx, and to Dr. H. J. Trenchard, to whose ward this patient was admitted.

\section{REFERENCES}

Absher, W. K., and Cline, F. (1949). Amer. Rev. Tuberc., 59, 643. Arblaster, P. G. (1950). Thorax, 5, 333.

Ajello, L. (1952). Personal communication.

Beadenkopf, W. G., and Loosli, C. G. (1951). J. Amer. med. Ass., 146,621 .

Blumberg, R. W., Ruchman, I., and Johansmann, R. J. (1949). Pediatrics, 3, 296.

Brandt, F. A. (1950). J. Path. Bact., 62, 259

Bunnell, I. L., and Furcolow, M. L. (1948). Publ. Hlth Rep. Wash., 63, 299.

Campbell, C. C., and Saslaw, S. (1951). Ibid., 66, 16.

Charr, R. (1953). Amer. Rev. Tuberc., 67, 376

Christie, A. (1951). Trans. Ass. Amer. Phys., 64, 147

$\longrightarrow$ and Peterson, J. C. (1946). J. Amer. med. Ass., 131, 658

Conant, N. F. (1941). J. Bact., 41, 563.

Crofton, J. (1950). Thorax, 5, 340.

Curtis, A. C., and Grekin, J. H. (1947). J. Amer. med. Ass., 134, 1217.

Darling, S. T. (1906). Ibid., 46, 1283.

Darling, S. T. (1906). Ibid., 46, 1283.

Dean, L. W. (1942). Arch. Otolaryng., Chicago, 36, 390.
De Monbreun, W. A. (1934). Amer. J. trop. Med., 14, 93.

De Monbreun, W. A. (1934).

Derry, D. C. L., Card, W. I., Wilson, R., and Duncan, J. T. (1942). Lancet, 1, 224.

Duncan, J.'T. (1947). Trans. roy. Soc. trop. Med. Hyg., 40, 364.

Emmons, C. W. (1949). Publ. Hlth Rep. Wash., 64, 892.

Emmons, (1952). Personal communication.

Furcolow, M. L. (1949). Publ. Hlth Rep. Wash., 64, 1363.

(1950). Ibid., 65, 965 .

(1952). Personal communication.

Emge, M. E., and Bunnell, I. L. (1948). Publ. Hlth Rep. Wash. 63,1290 .

High, R. H., and Allen, M. F. (1946). Ibid., 61, 1132.

Mantz H. L., and Lewis, I (1947). Ibid., 62, 1711.

Gammell, E. B., and Breckenridge, R. L. (1949). Ann. Otol., St.

Louis, 58, 249.
Heilbrunn, I. B., and Cain, A. R. (1950). J. Mo. med. Ass., 47, 503.

High, R. H., Zwerling H. B., and Furcolow, M. L. 1947). 'Publ. Hlth Rep. Wash., 62, 20.

Hodgson, C. H., Weed, L. A., and Clagett, O. T. (1950). J. thorac. Surg., 20, 97 .

Hulse, W. F. (1951). Arch. Otolaryng., Chicago, 54, 65.

Hutchison, H. E. (1952). J. Path. Bact., 64, 309.

Israel, H. L., De Lamater, E., Sones, M., Willis, W. D., and Mirmelstein, A. (1952). Amer. J. Med., 12, 252.

Jelliffe, D. B. (1949). J. trop. Med. Hyg., 52, 177.

Kirsch, E. (1951). Z. Tropenmed. Parasit., 3, 86.

Klingberg, W. G. (1950). J. Pediat., 36, 728.

LeJeune, F. (1950). Ann. Otol., St. Louis, 59, 821.

Limerick, C. B. (1951). Brit. med. J., 1, 885.

Locket, S., Atkinson, E. A., Grieve, W. S. M., and Bridson, E. (1953). Ibid., $2,857$.

Meleney, H. E. (1940). Amer. J. trop. Med., $20,603$.

Mochi, A., and Edwards, P. Q. (1952). Bull. Wld Hlth Org., 5, 259.

Olson, B. J., Bell, J. A., and Emmons, C. W. (1947). Amer. J. publ. Hlth, 37, 441.

Palmer, C. E. (1946). Publ. Hlth Rep. Wash., 61, 475.

Parsons, R. J., and Zarafonetis, C. J. D. (1945). Arch. intern. Med., 75, 1 .

Pratt, P. T., Schwartz, S. O., and Ehrlich, L. (1950). Ibid., 85, 893.

Prior, J. A., and Allen, M. L. (1947). Publ. Hlth Rep. Wash., 62, 1608.

Prior, J. A., and Allen, M. L. (1947). Publ. Hith Rep. Wash.

Puckett, T. F. (1953). Amer. Rev. Tuberc., 67, 453.

Rawson, A. J., Collins, L. H., and Grant, J. L. (1948). Amer. J. med. Sci., $215,363$.

Roberts, S. E., and Forman, F. S. (1950). Ann. Otol., St. Louis, 59, 809.

Rodger, R. C., Terry, L. L., and Binford, C. H. (1951). Amer. J. clin. Path., 21, 153.

Sakula, A. (1953). Tubercle, 34, 18.

Salvin, S. B. (1947). Proc. Soc. exp. Biol., N.Y., 66, 342.

Schultz, A. (1937). Verh. dtsch. path. Ges., 30, 483.

Schwartz, B., and Spitz, L. J. (1952). Arch. intern. Med., 89, 541.

Silverman, F. N. (1950). Amer. J. Roentgenol., 64, 747.

Sontag, L. W., and Allen, J. E. (1947). J. Pediat., 30, 657.

Stott, H. (1954). Brit. med. J., 1, 22.

Tenenberg, D. J., and Howell, A. (1948). Publ. Hlth Rep. Wash.,

63, 163.

Thomas, W. C., and Morehead, R. P. (1943). N.C. med. J., 4, 378. Child., 79, 806. 